\title{
Physician Empathy Towards Patients: A Survey in Iranian Teaching Hospitals
}

\author{
Ali Mohammadi ${ }^{*}$ Korosh Kamali $^{1}$ \\ ${ }^{1}$ Department of Public Health, Faculty of Health, Zanjan University of Medical sciences, Zanjan, Iran.
}

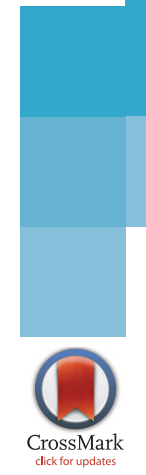

\begin{abstract}
Background and Objectives: Empathy is a key element of physician-patient relations, playing a significant role in effectiveness of health care. The subject, however, has received limited academic attention in an Iranian context. This study, thus, aimed to explore the empathic attitudes of physicians towards patients and the possible difference of empathy among of doctors of various specialties.

Methods: All 142 specialist physicians practicing in teaching hospitals of Zanjan city (Northern Iran) were surveyed. The 20-item Jefferson Scale of Physician Empathy (JSPE) was used as the study tool. The answers were quantified on a 7-point Likert-type scale ranging from strongly disagree (1) to strongly agree (7). Data were summarized using descriptive statistical methods. The mean values were compared by $t$ test and analysis of variance (ANOVA).

Findings: The overall empathy score averaged at $100.7 \pm 17.7$ falling within the intermediate range (Max. $=140)$. While the highest score of the empathy dimensions was received by compassionate care (5.22), the lowest score was belonged to standing in the patient's shoes (4.89). Female physicians exhibited significantly higher empathy level $(107.3 \pm 15.6)$ compared with their male counterparts $(96.4 \pm 16.6)(P=.003)$. The empathy score mean was found to be significantly higher among physicians with human-centric specialties (113.05 \pm 16.2$)$ as compared with technology-centric, tool-centric, and non-primary care specialties which scored $98 \pm 12.12,98.2 \pm 18.7$, and 97.1 \pm 15.9 , respectively $(F=5.14, P=.002)$.

Conclusions: The observed level of empathy among physicians indicates a large room for improvement, particularly among male doctors and technology/tool-centric specialties. Considering the crucial role of clinical empathy in patient satisfaction and outcome, our results recommend further studies to examine the issue on larger scales and devise intervention strategies if the observed gap will be confirmed.
\end{abstract}

Keywords: Physician-patient relations, Empathy, Patient satisfaction, Patient outcome, Health care effectiveness

\section{Background and Objectives}

Empathy is referred to as the ability to understand experiences and feelings of another individual. ${ }^{1}$ In the healthcare context, empathy is described as the ability of a care provider to understand emotional needs of their patient and is considered as a key component of patient-physician relationship, ${ }^{2}$ which according to Hippocrates is a symbolic link that helps in the effectiveness of care. ${ }^{3}$ Thus, empathy is mentioned as a humanistic dimension in the patient's care. ${ }^{3}$

The concept of empathy is generally categorized into 2 related domains: cognitive domain and affective (emotional) domain. While the cognitive domain accounts for

*Corresponding Author: Ali Mohammadi, Department of Public Health, Faculty of Health, Zanjan University of Medical sciences, Zanjan, Iran. Tel: +982433760514, Email: ali@zums.ac.ir the ability of one to understand experiences of another individual, the emotional domain concerns the capacity on one to communicate this understanding or to share feelings with others. ${ }^{4,5}$

Mounting evidence indicates that patients who enjoy the empathy of their physicians generally express higher levels of satisfaction, comfort, and self-efficacy. ${ }^{5,6}$ By developing trust and openness in patients, an empathic attitude enables the physicians to make more accurate diagnoses and prescribe more efficiently. ${ }^{6}$ More importantly, an empathetic relationship between physician and patient has been associated with improved healthcare outcome. $^{3-6}$ In addition, empathetic approaches to patient care is a source for greater adherence of the patient to treatment, decreased stress levels, and lower rate of medical errors, and ultimately higher performance of health care system..$^{7-9}$ 
Clinical empathy is a communicative skill and a key principle of the patient-centered care. In the past decade, medical educators and professional health practitioners have increasingly emphasized the humanistic values and the clinical importance of empathy among medical students and specialist physicians. ${ }^{2,10}$ Nonetheless, the issue has been poorly explored in an Iranian context. This study, thus, aimed to explore the empathic attitudes of specialist physicians towards patients and the possible influence of specialty on empathy level.

\section{Methods}

\section{Study Design}

This descriptive cross-sectional study was conducted among all 142 specialist physicians practicing in teaching hospitals of Zanjan city (Northern Iran).

\section{Data Collection}

Empathy was measured using a revised version of the Jefferson Scale of Physician Empathy (JSPE). This scale was originally developed and validated by Hojat et al to evaluate the perception of medical students on the empathy of the physicians towards the patients (the "S" version). ${ }^{11,12}$ Several studies that used JSPE for measurement of empathy have demonstrated the validity and reliability of this scale. ${ }^{13-16}$ JSPE is a self-report questionnaire), ${ }^{15}$ comprising 20 questions (items) related to 3 dimensions of Perspective takings (10 items), Compassionate care (8 items), and Standing in patients shoes (2 items). The questionnaire was administered through the education offices of teaching hospitals. The responses are quantified based on 7-point Likert-type scale, ranging from 1= "strongly disagree" to $7=$ "strongly agree". ${ }^{7}$ Reliability of the scale in our study was explored using a pilot sample of 20 physicians. The Cronbach $\alpha$ was found to be. 80 for the overall scale, and .81, .74, and .72 for perspective takings, compassionate care, and standing in patient's shoes, respectively, indicating adequate reliability of the scale and its subscales. ${ }^{17}$

To explore possible influence of specialty of empathy, the physicians' specialties were categorized into 2 groups; the main specialties (internal medicine, obstetrics, pediatrics, and surgery), and miscellaneous specialties. Further, we also classified physicians' specialties were into 4 groups of the technology-centeric specialties (surgery, orthopedics, and ophthalmology), the tool-centeric specialties (radiology, pathology, and anesthesiology); people-centeric (related to primary care) specialties (internal medicine, obstetrics, and pediatrics), and specialties non-related to primary care to gain more insight into specialty-empathy relationship. ${ }^{14}$

\section{Statistical Analysis}

Data were summarized using descriptive statistical methods. Mean values were compared by independent samples $t$ test and analysis of variance (ANOVA). $P<.05$ was considered as the statistical significance. All analyses were carried out using SPSS version 16 software package.

\section{Ethical Issues}

The Ethical Committee of Zanjan University of Medical Sciences approved the study. The purpose of the study and how the data would be used was explained to the respondents in a cover letter. To ensure the participants on the confidentiality of their responses the questionnaires were asked to be completed anonymously.

\section{Results}

\section{Characteristics of the Participants}

Of 130 physicians who agreed to complete the questionnaire, 120 returned valid questionnaires (response rate $=92 \%$ ). While $61 \%$ of the participants were male, $32.7 \%$ held a main specialty. The majority of the participants were in the age group of 36-45 years and the mean age of the respondents was 40.92 years.

\section{Descriptive Analysis}

The empathy's score mean was found to range from 96 to 100 averaging $100.7 \pm 17.7$. Table 1 shows the scores received by each dimension and item of JSPE scale. While the highest and lowest score mean of the items was related to "Physicians' understanding of their patients' feelings and the feelings of their patients' families do not influence medical or surgical treatment." (5.64) and "Physicians should try to think like their patients in order to render better care" (3.94), respectively. Compassionate care received the highest score relative to its maximum value $(74.5 \%)$, followed by standing in the patient's shows (70.7\%), and perspective taking (69.9\%).

\section{Comparison Among Gender, Age, and Specialty Groups}

The level of empathy in female physicians (107.3 \pm 15.6$)$ was found to be significantly higher than that in their male counterparts $(96.4 \pm 16.6)(P=.003)$. Inter-gender comparison also showed significantly higher compassionate care $(P=.007)$ and perspective takings $(P=.016)$ among female physicians compared with male doctors (Table 2).

While the highest score mean of empathy and its dimensions was related to the age group of 36-45 years (105.3), the difference between age groups was not significant (Table 3). 
Table 1. Means and SD Empathy's Dimensions Among the Specialist Physician as Measured by JSPE $(n=120)$

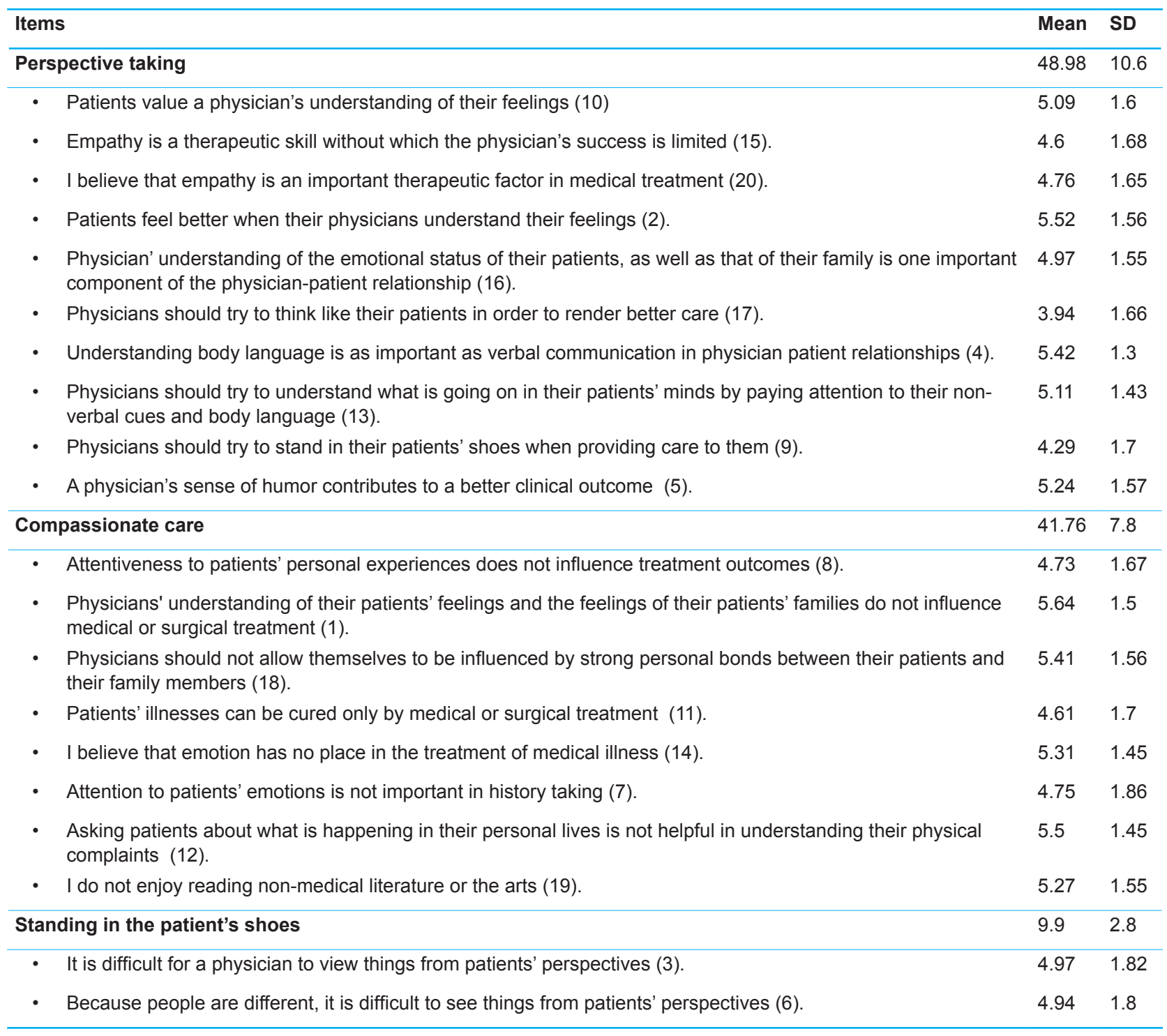

Table 2. Comparison of Score Mean (SD) of Empathy and its Dimensions Among Male and Female Physicians

\begin{tabular}{lcccc}
\hline Empathy and its Dimensions & Total & Male & Female & Significance of Difference Between Genders \\
\hline Empathy & $100.7(15.6)$ & $94.6(16.6)$ & $107.3(15.6)$ & 0.003 \\
Perspective taking & $48.98(10.6)$ & $46.8(9.8)$ & $52.35(11.9)$ & 0.016 \\
Compassionate care & $41.76(7.8)$ & $40.03(7.8)$ & $44.48(7.29)$ & 0.007 \\
Standing in the patient's shoes & $9.9(2.8)$ & $9.56(2.57)$ & $10.48(3.21)$ & $>0.05$ \\
\hline
\end{tabular}

Table 3. Comparison of Score Mean (SD) of Empathy and its Dimensions Among Physicians of Different Age Groups

\begin{tabular}{lccccc}
\hline Age Group & $\begin{array}{c}\text { Technology- } \\
\text { Centric } \\
\text { Mean (SD) }\end{array}$ & $\begin{array}{c}\text { Tool - Centric } \\
\text { Mean (SD) }\end{array}$ & $\begin{array}{c}\text { Non-related to } \\
\text { Primary Care } \\
\text { Mean (SD) }\end{array}$ & $\begin{array}{c}\text { Human- } \\
\text { Centric }\end{array}$ & $\begin{array}{c}\text { Significance of Difference } \\
\text { Between Males and Females }\end{array}$ \\
\hline Empathy & $98(12.21)$ & $98.2(18.7)$ & $97.1(15.9)$ & $113.05(16.2)$ & $>0.05$ \\
Perspective taking & $48.5(5.05)$ & $47.75(11.05)$ & $46.96(10.47)$ & $46.96(12.15)$ & $>0.05$ \\
Compassionate care & $38.7(7.37)$ & $41.3(8.62)$ & $40.46(7.36)$ & $46.05(5.7)$ & $>0.05$ \\
Standing in the patient's shoes & $10.66(2.23)$ & $9.17(2.9)$ & $9.5(2.8)$ & $11.88(2.7)$ & $>0.05$ \\
\hline
\end{tabular}


Table 4. Comparison of Score Mean and SD of Empathy and its Dimensions Among Physicians of Different Specialties

\begin{tabular}{lccc}
\hline \multirow{2}{*}{ Age Group } & \multicolumn{2}{c}{ Specialty } & \multirow{2}{*}{ Significance of Difference } \\
\cline { 2 - 3 } & $\begin{array}{c}\text { Miscellaneous } \\
\text { Mean (SD) }\end{array}$ & $\begin{array}{c}\text { Main } \\
\text { Mean (SD) }\end{array}$ & 0.002 \\
\hline Empathy & $97.7(17.7)$ & $106.8(16.3)$ & $>0.05$ \\
Perspective taking & $47.8(10.3)$ & $51.38(11.7)$ & 0.04 \\
Compassionate care & $40.6(8.3)$ & $44.1(6.3)$ & 0.001 \\
Standing in the patient's shoes & $9.2(2.8)$ & $11.3(2.4)$ & \\
\hline
\end{tabular}

In addition, the overall score of empathy was found to be significantly higher among physicians with main specialties (106.8) in comparison to those with and miscellaneous specialties $(97.7)(P<.05)$. The former group has also shown a higher score mean in standing in patients' shoes compared with the latter $(P<.05$; Table 4$)$.

Comparison of empathy level between various categories of medical specialty revealed a significantly higher empathy score among physicians with human-centric specialties compared with other groups $(\mathrm{F}=5.14, P=.002)$.

\section{Discussion}

This study aimed to evaluate empathy of specialist physicians toward the patients in teaching hospitals of Zanjan province of Iran. Our survey identified an intermediate level of empathy towards the patients among the surveyed physicians. Although the score of all empathy dimensions relative to their maximums were comparable, Compassionate care gained the highest relative score. This indicates that physicians consider the emotional factors in patient care and medical practice to satisfactory degrees. Emotional interactions, such as positive talk, eye contact, touch, and kind behaviors, can lead to high patient satisfaction. ${ }^{18,19}$ Standing at the next ranks, the relative scores of standing in patients' shoes and perspective caring indicates the need for improving theoretical attitudes of the physics towards the clinical significance of empathy and to strength their relevant psychological skills. Both of these needs would be at least partially met by training. 2,10

The average level of empathy observed in our physicians (100.7) compares with that in some previous studies which have used a similar scale. For instance, Shariat et al reports an empathy level of 101.4 in Iranian medical students with the highest and the lowest scored dimensions to be compassionate care and standing in patients' shoes, respectively. ${ }^{15}$ Similarly, a survey among medical students in Kuwait, identified an empathy score mean of 104.6. ${ }^{20}$ Nonetheless, the average empathy level as observed in our physicians was lower as compared with the studies of Di Lillo et al (Italy), ${ }^{3}$ Williams et al (Australia), ${ }^{9}$ Soncini et al (Italy) ${ }^{10}$ and Sherman et al (United States), ${ }^{21}$ all of which reporting an upper-intermediate level of empathy.

Our finding that female physicians express higher level of empathy compared with their male counterparts is congruent to several previous studies from various countries. $^{9,10,21-23}$ We also observed that physicians with main specialties (internal medicine, obstetrics, and pediatrics specialties) are more empathic toward the patients compared with other physicians. In addition, the level of empathy was found to be higher among physicians with human-centric specialties. Both of these observations are consistent with several previous literatures reporting the same pattern of relationship between medial specialty and empathy level. ${ }^{3,11,14,24}$

Physicians' empathy towards patients is both a humanitarian aspect of professional medicine and a major component of physician-patient relationship. ${ }^{25}$ Our observation that a sample of Iranian physicians showed an intermediate level of empathy towards patients recommends conduction of further large-scale studies to gain nation-wide insight to the situation. Particularly, our physicians showed relatively low capability to understand life and disease-related problems from the view pints of their patients. Therefore, measures such as psychological training should be taken to empower physicians in this skill. According to our findings male physicians are the prime target group for such interventions. Further, in order to enhance the overall sense of empathy in clinical staff, empathic interactions with patients need to be valued and appreciated by the health policymakers and hospital managers. ${ }^{26}$ The general congruence of our results with previous reports suggest that the experience and policies of other countries in improving empathy among clinical staff may be adopted in an Iranian context or may at least be inspiring.

\section{Study Limitation}

The fact that the sample size was limited and was taken from hospitals of a single province hinders generalization of the results in the Iranian context. Our results therefore should be treated as a motivation for further con- 
firmatory studies.

\section{Conclusions}

This study explored the level of empathy and its dimensions among a sample of Iranian physicians. The empathy among the surveyed doctors was found to be at intermediate level and lower than that reported from several developed countries. Similar to previous studies, we found the male physicians and doctors with technology/tool-centric specialties to show lower empathic attitudes towards the patients. Considering the crucial role of clinical empathy in patient satisfaction and outcome, our results highlights the need for further studies to explore the issue on larger scales and develop intervention strategies if the present results will be confirmed.

\section{Competing Interests}

The authors declare no competing interests.

\section{Authors' Contributions}

The authors made the same contributions to this study.

\section{Acknowledgments}

The authors would like to thank the Research Vicechancellor of the Zanjan University of Medical Sciences for providing financial support to this project.

\section{References}

1. Cox CL, Uddin LQ, Di Martino A, et al. The balance between feeling and knowing: affective and cognitive empathy are reflected in the brain's intrinsic functional dynamics. Soc Cogn Affect Neurosci. 2012;7(6):727-737. doi:10.1093/ scan/nsr051.

2. Tavakol S, Dennick R, Tavakol M. Psychometric properties and confirmatory factor analysis of the Jefferson Scale of Physician Empathy. BMC Med Educ. 2011;11:54. doi:10.1186/s12909-016-0763-5.

3. Di Lillo M, Cicchetti A, Lo Scalzo A, Taroni F, Hojat M The Jefferson Scale of Physician Empathy: preliminary psychometrics and group comparisons in Italian physicians. Acad Med. 2009;84:1198-1202. doi:10.1097/ ACM.0b013e3181b17b3f.

4. Hojat M, Spandorfer J, Louis DZ, Gonnella JS. Empathic and sympathetic orientations toward patient care: conceptualization, measurement, and psychometrics. Acad Med. 2011;86(8):989-995. doi:10.1097/ACM.0b013e31822203d8.

5. Hojat M, Gonnella JS, Mangione S, et al. Empathy in medical students as related to academic performance, clinical competence and gender. Med Educ. 2002;36(6):522-527.

6. Quince TA, Parker RA, Wood DF, Benson J. Stability of empathy among undergraduate medical students: a longitudinal study at one UK medical school. BMC Med Educ. 2011;11:90. doi:10.1186/1472-6920-11-90.

7. Mehrabian A, Epstein NA: A measure of emotional empathy. J Pers. 1972;40:525-543

8. Dewberry C. Statistical Methods for Organizational Research. London: Routledge and Taylor Francis; 2005.

9. Williams B, Brown T, McKenna L, et al. Student empathy levels across 12 medical and health professions: an interventional study. J Compassionate Health Care. 2015;2(4):7-12.

10. Soncini F, Silvestrini G, Poscia A, et al. Public Health Physicians and Empathy. Are we really empathic? The Jefferson Scale applied to Italian resident doctors in Public Health. Eur J Public Health. 2013;23(1):13-16.

11. Hojat M, Gonnella JS, Nasca TJ, Mangione S, Vergare M, Magee M. Physician empathy: definition, components, measurement, and relationship to gender and specialty. Am J Psychiatry. 2002;159(9):1563-1569. doi:10.1176/appi. ajp.159.9.1563

12. Hojat M, Mangione S, Nasca TJ. The Jefferson scale of physician empathy: development and preliminary psychometric data. Educ Psychol Meas. 2001;61(2):349365.

13. Kataoka HU, Koide N, Hojat M, Gonnella J. Measurement and correlates of empathy among female Japanese physicians. BMC Med Educ. 2012;12:48. doi:10.1186/14726920-12-48.

14. Shariat S V, Keykhavoli A. Empathy level in Iranian medical residents in IUMS (Persian). Journal of Iran Psychiatrics and Clinical Psychology. 2011;16(3):248- 256.

15. Shariat SV, Habibi M. Empathy in Iranian medical students: measurement model of the Jefferson Scale of Empathy. Med Teach. 2013;35(1):e913-e918. doi:10.3109/014215 9X.2012.714881.

16. Shariat S V, Eshtad E, Ansari S. Empathy and its correlates in Iranian physicians: a preliminary psychometric study of the Jefferson Scale of Physician Empathy. Med Teach. 2010;32:e417-e421.

17. Cronbach LJ. Coefficient alpha and the internal structures of tests. Psychometrica. 1951;16(3):297-334.

18. Magalhães E, Salgueira AP, Costa P, Costa MJ. Empathy in senior year and first year medical students: a cross-sectional study. BMC Med Educ. 2011;11:52. doi:10.1186/1472-692011-52.

19. Van Winkle LJ, Fjortoft N, Hojat M. Impact of a workshop about aging on the empathy scores of pharmacy and medical students. Am J Pharm Educ. 2012;76(1):9. doi:10.5688/ ajpe 7619 .

20. Hasan S1, Al-Sharqawi N, Dashti F, et al. Level of empathy among medical students in Kuwait University, Kuwait. Med Princ Pract. 2013;22(4):385-9. doi:10.1159/000348300. 
21. Sherman JJ, Cramer A. A measurement of changes in empathy during dental school. J Dent Educ. 2005;69 (3):338-345.

22. Kataoka HU, Koide N, Hojat M, Gonnella JS. Measurement and correlates of empathy among female Japanese physicians. BMC Med Educ. 2012;12:48. doi:10.1186/14726920-12-48.

23. Fields SK, Mahan P, Tillman P, Harris J, Maxwell K, Hojat M. Measuring empathy in healthcare profession students using the Jefferson Scale of Physician Empathy: Health provider student version. J Interprof Care. 2011;25(4):287-293. doi:1 0.3109/13561820.2011.566648.

24. Kataoka HU, Koide N, Ochi K, Hojat M, Gonnella JS. Measurement of empathy among Japanese medical students: psychometrics and score differences by gender and level of medical education. Acad Med. 2009;84:11921197.

25. Hojat M, Louis DZ, Markham FW, Wender R, Rabinowitz C, Gonnella JS. Physicians' empathy and clinical outcomes for diabetic patients. Acad Med. 2011;86(3):359-364. doi:10.1097/ACM.0b013e3182086fe1.

26. Santo LD, Pohl S, Saiani L, Battistelli A. Empathy in the emotional interactions with patients. Is it positive for nurses too? J Nurs Educ Pract. 2014;4(2):74-81.

\section{Please cite this article as:}

Mohammadi A, Kamali K. Physician empathy towards patients: a survey in Iranian teaching hospitals. Int $\mathrm{J}$ Hosp Res. 2016;5(2):52-57. doi:10.15171/ijhr.2016.10. 